\title{
Chromitite layers require the existence of large, long-lived, and entirely molten magma chambers
}

Rais Latypov ( $\square$ rais.latypov@wits.ac.za )

University of the Witwatersrand https://orcid.org/0000-0002-8158-5949

Sofya Chistyakova

University of the Witwatersrand

\section{Stephen Barnes}

CSIRO

\section{Belinda Godel}

CSIRO

\section{Gary Delaney}

CSIRO Data61, Clayton South

\section{Paul Cleary}

CSIRO Data61, Clayton South

\section{Viktor Radermacher}

Evolutionary Studies Institute https://orcid.org/0000-0001-6524-7811

lan Campbell

Australian National University https://orcid.org/0000-0001-8578-0154

Kudakwashe Jakata

European Synchrotron Radiation Facility https://orcid.org/0000-0001-7217-2774

\section{Article}

Keywords: molten magma chambers, Bushveld Complex, stratiform chromitites

Posted Date: May 26th, 2021

DOl: https://doi.org/10.21203/rs.3.rs-443338/v1

License: (c) (i) This work is licensed under a Creative Commons Attribution 4.0 International License.

Read Full License 
1 Chromitite layers require the existence of large, long-lived, and

2 entirely molten magma chambers

4 Rais Latypov $^{1 *}$ Sofya Chistyakova $^{1}$, Stephen J. Barnes ${ }^{2}$, Belinda Godel ${ }^{2}$, Gary W. Delaney ${ }^{3}$,

5 Paul W. Cleary ${ }^{3}$, Viktor J. Radermacher ${ }^{4}$, Ian Campbell ${ }^{5}$, and Kudakwashe Jakata ${ }^{2,6}$

6

7 An emerging and increasingly pervasive school of thought is that large, long-lived and

8 largely molten magma chambers are transient to non-existent in Earth's history $^{1-13}$.

9 These ideas attempt to supplant the classical paradigm of the 'big magma tank' chambers

10 in which the melt differentiates, is replenished, and occasionally feeds the overlying

11 volcanoes ${ }^{14-23}$. The stratiform chromitites in the Bushveld Complex - the largest

12 magmatic body in the Earth's crust ${ }^{24}$ - however, offers strong contest to this shifting

concept. Several chromitites in this complex occur as layers up to 2 metres in thickness

and more than 400 kilometres in lateral extent, implying that chromitite-forming events were chamber-wide phenomena ${ }^{24-27}$. Field relations and microtextural data, specifically the relationship of 3D coordination number and grain size, indicate that the chromitites grew as a 3D framework of touching chromite grains directly at the chamber floor from a melt saturated in chromite only ${ }^{28-30}$. Mass-balance estimates dictate that a 1 to $4 \mathrm{~km}$ thick column of this melt ${ }^{26,31,32}$ is required to form each of these chromitite layers.

\footnotetext{
${ }^{1}$ School of Geosciences, University of the Witwatersrand, Johannesburg, South Africa; ${ }^{2}$ CSIRO Mineral Resources, Kensington, Perth, WA 6151, Australia; ${ }^{3}$ CSIRO Data61, Clayton South, VIC 3169, Australia; ${ }^{4}$ Evolutionary Studies Institute, University of the Witwatersrand, Private Bag 3, 2050, South Africa; ${ }^{5}$ Australian National University, Canberra ACT 0200, Australia; ${ }^{6}$ European Synchrotron Radiation Facility (ESRF), France. *Corresponding Author, email: Rais.Latypov@wits.ac.za
} 
from the magma chamber ${ }^{24,26}$. We therefore argue that the very existence of thick and

\section{buttress the classical paradigm of 'big magma tank' chambers.}

For over a century, the classical paradigm of magma chambers has underpinned all models of the Earth's magmatism. This paradigm envisages a magma chamber as a large body of the molten, long-lived, and slowly fractionating magma ('a big magma tank') enclosed in crustal rocks $^{14-23}$. In recent years, this classic view of a magma chamber garnered increased scrutiny from many geoscientists who contend that such long-lived and largely molten 'big tank' magma chambers are either very short-lived or never existed in Earth's history ${ }^{1-13}$. For instance, some igneous petrologists maintain that tectonic processes that create open spaces in the crust at any tectonic setting are so slow that the liquid-dominated magma bodies of any composition can hardly form ${ }^{1,2}$. Instead, they have suggested that plutons grow incrementally from numerous sills/dykes a few meters thick that cool and may even become totally solidified between injections ${ }^{1,2}$. Similarly, most volcanologists have abandoned the classic paradigm because the geophysical surveys have failed to detect any present-day eruptible magma bodies in the Earth's crust ${ }^{4,8}$. As an alternative, they proposed the existence of transcrustal mushy systems (including mushy reservoirs for mafic layered intrusions ${ }^{4}$ ) that are formed in the crust from numerous collating intrusions. The transcrustal systems contain only small melt lenses that are produced by compaction ${ }^{3,7}$ or tectonic destabilization ${ }^{4,8}$ of the crystal mush and exist for only a very short period of time before accumulating and erupting as lavas on the Earth's surface $^{1-8}$. Yet another group of mafic plutonists, influenced by out-of-sequence zircon geochronological data ${ }^{9,10,13}$, have proposed that mafic plutons do not require the existence of large magma chambers ${ }^{12}$. These are rather produced as a stack of randomly-emplaced sills, 
46 with successive crystal-rich pulses often invading pre-existing cumulates ${ }^{9-13}$. In stark contrast

47 to these 'anti-magma-chamber' approaches, we argue here that the existence of large magma

48 chambers is indicated by laterally extensive layers of chromite-rich cumulates, which require

49 many times their own volume of magma to supply the key component, chromium $(\mathrm{Cr})$. We

50 present here field and microtextural data from massive chromitites of the Bushveld Complex

51 that indicate that 'big magma tank' chambers in the Earth's crust are a reality that cannot and

52 should not be dismissed.

\section{The enormous extent of chromitite layers}

55 The 2.05 Ga Bushveld Complex in South Africa (Fig. 1a) is the largest mafic-ultramafic 56 layered intrusion in Earth's crust; totalling to about $600,000 \mathrm{~km}^{3}$ of igneous rocks ${ }^{24,25}$. The 57 complex consists of several parts, the western, eastern and northern limbs being the largest, 58 and is subdivided stratigraphically into five major units - the Marginal, Lower, Critical, Main, 59 and Upper Zones, comprising a total thickness of 7 to $9 \mathrm{~km}^{24,25}$. The Bushveld Complex contains $>80 \%$ of the Earth's known chromium resources ${ }^{33}$, an element critical to improving the material properties of steel, making this magmatic body an object of perennial study. The chromium is hosted within 14 principal layers of massive chromitites, mostly confined to the

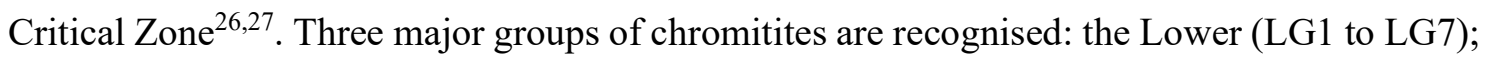
Middle (MG0 to MG4); and Upper Groups (UG1 to UG3) ${ }^{27}$. The thickness of individual chromitite layers ranges from a few decimeters to 2 meters. Mining activities have allowed most of these layers to be traced across the entire Bushveld Complex ${ }^{27}$. Remarkably, the vertical distribution of platinum-group elements across some of these chromitites are nearly identical in places that are separated laterally by over $300 \mathrm{~km}^{26}$. The vast lateral extent and mineralogical uniformity of chromitite layers indicate that the process responsible for their 

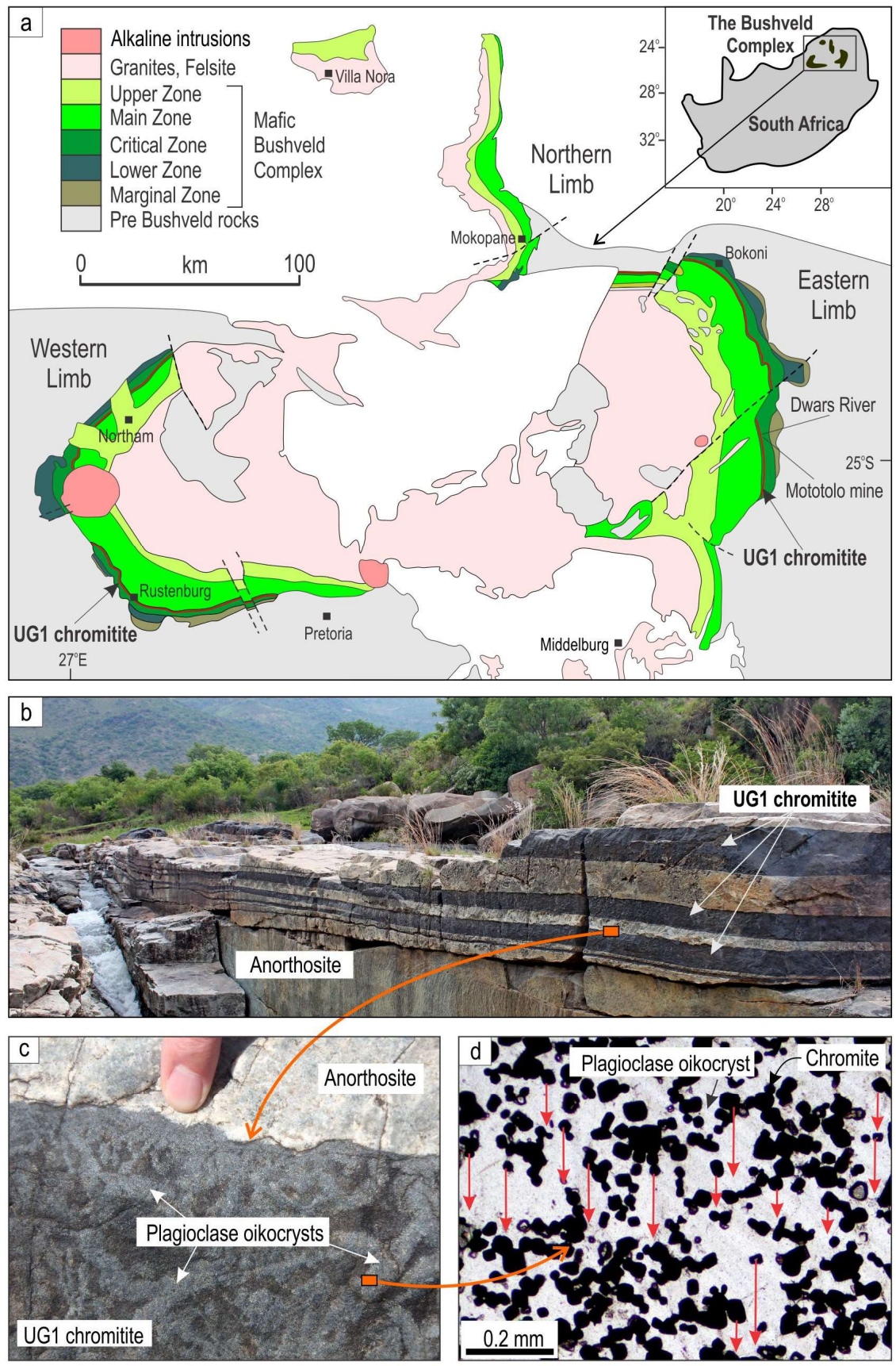

Fig. 1. A notable lack of textural evidence for gravity settling of chromite crystals within a UG1 chromitite of the Bushveld Igneous Complex, South Africa. a, Location and generalized geological map of the Bushveld Complex emphasizing its enormous size. Note that this is just an erosional remnant of the complex so that its original size was even larger. The immense lateral extent of the chromitite layers $(>350-400 \mathrm{~km})$ in this complex is illustrated here by the UG1 chromitite that occurs at the top of the Critical Zone. Also indicated are places from which the studied samples were obtained. Modified from reference ${ }^{28}$. b, Panoramic view of a few sublayers of the UG1 chromitite in the anorthosite footwall at the Dwars River, Eastern Limb. c, A close-up photograph of the top part of the UG1 chromite sublayer. Note large plagioclase oikocrysts enclosing numerous small crystals of cumulus chromite (chadacrysts). d, Photograph of a thin-section (under plane polarized light) of the UG1 chromitite showing isolated chromite grains and their loose clusters enclosed by a single large oikocryst of plagioclase. Red arrows emphasize that chromite grains show no tendency to gravitate downwards despite a high porosity of the framework ( $\sim 65$ vol.\%). Sample HX-07-153.33, Mototolo mine, Eastern Limb. 
formation has been working synchronously in all parts of the superlarge chamber to produce the same chromitite layer over lateral distances of up to $400 \mathrm{~km}$ (e.g., UG1 in Fig. 1a).

\section{Field and textural evidence for in situ growth of chromite}

The nature of this chamber-wide process can be constrained from field and textural features of massive chromitite layers such as the 2 m-thick UG1 chromitite - the thickest and the best exposed layer in the entire complex (Fig. 1b). This chromitite shows remarkable field relationships with its respective footwall rocks. In addition to its occurrence on the planar portions of the chamber floor, this chromitite develops within potholes, roughly circular depressions in which footwall rocks are missing due to magmatic erosion ${ }^{28,34}$. In these areas, the planar UG1 chromitite that occurs along the periphery of the potholes commonly passes, without any apparent changes in thickness and texture, into the steeply dipping, subvertical and even overhanging UG1 chromitite in the interior of potholes ${ }^{28,34}$ (Extended Data Fig. 1). This field observation strongly argues against the formation of the UG1 chromitite, both on the planar and overhanging portions of the chamber floor, by processes involving gravity-induced settling of chromite through either the resident melt ${ }^{35-38}$ or a crystal-rich mush ${ }^{39,40}$. The simplest alternative mechanism is in situ growth of chromite directly at the chamber floor from a chromite-only-saturated melt ${ }^{28,30}$. This is the only process that allows the chromitite layer to cover all the planar and irregular margins, even the places where gravity-settling of chromite grains is physically impossible (i.e., "gravity-settling shadows" in which dips are overturned $^{28,34}$ ) (Extended Data Fig. 1).

An intriguing challenge here is to decipher how in situ growth of chromite is recorded in the texture of massive chromitites themselves. We have re-visited the UG1 chromitite from the classical Dwars River locality ${ }^{29}$ (Fig. 1b) where it is composed of $25-50$ vol\% of cumulus 
chromite that occurs as separate idiomorphic grains or clumps of grains that are smaller than $0.1 \mathrm{~mm}$ in size (Fig. 1c, d). The chromite grains are enclosed within much larger oikocrysts of plagioclase (up to $5-10 \mathrm{~cm}$ in size) that are clearly visible in outcrops (Fig. 1c). The traditional interpretation of such layers in the frame of gravity settling models is that chromite was the first to settle on the chamber floor ${ }^{35-38}$ followed, after some period of post-depositional cooling, by in situ growth of plagioclase oikocrysts from the interstitial melt in a mushy chromitite. An important point is that settling chromite grains have enough time to reach the chamber floor and start growing there. The subsequently forming oikocrysts may capture and arrest chromite from experiencing further growth, producing snapshots of an immature solidification front.

A close look at the UG1 texture (Fig. 1d) raises, however, a simple but fundamental quandary. Chromite is almost twice as dense as a basaltic melt $\left(4,800 \mathrm{~kg} / \mathrm{m}^{3}\right.$ and $2,600 \mathrm{~kg} / \mathrm{m}^{3}$, respectively) and is expected to settle to the chamber floor in a random closely-packed lattice in which all adjacent chromite grains are touching each other. However, this is not the case as chromite occurs as individual grains and clumps of grains that are 'suspended' within plagioclase oikocrysts (Fig. 1d). This observation leads to a critical question: why have the chromite grains/clumps failed to sink towards the chamber floor despite being much denser than the host melt? A potential clue to this puzzle is that the chromite grains in the UG1 layer appear to be arranged in chain-like aggregates ${ }^{41,42}$.

\section{Three-dimensional framework of chromite crystals}

The analysis and quantification of chromitite in three-dimensions (3D) using high-resolution X-ray computed tomography (HRXCT) revealed that nearly all chromite grains (97 vol\%) from the UG1 chromitite are interconnected to form a single continuous 3D framework composed of many thousands grains that extend across multiple plagioclase and pyroxene oikocrysts (Fig. 


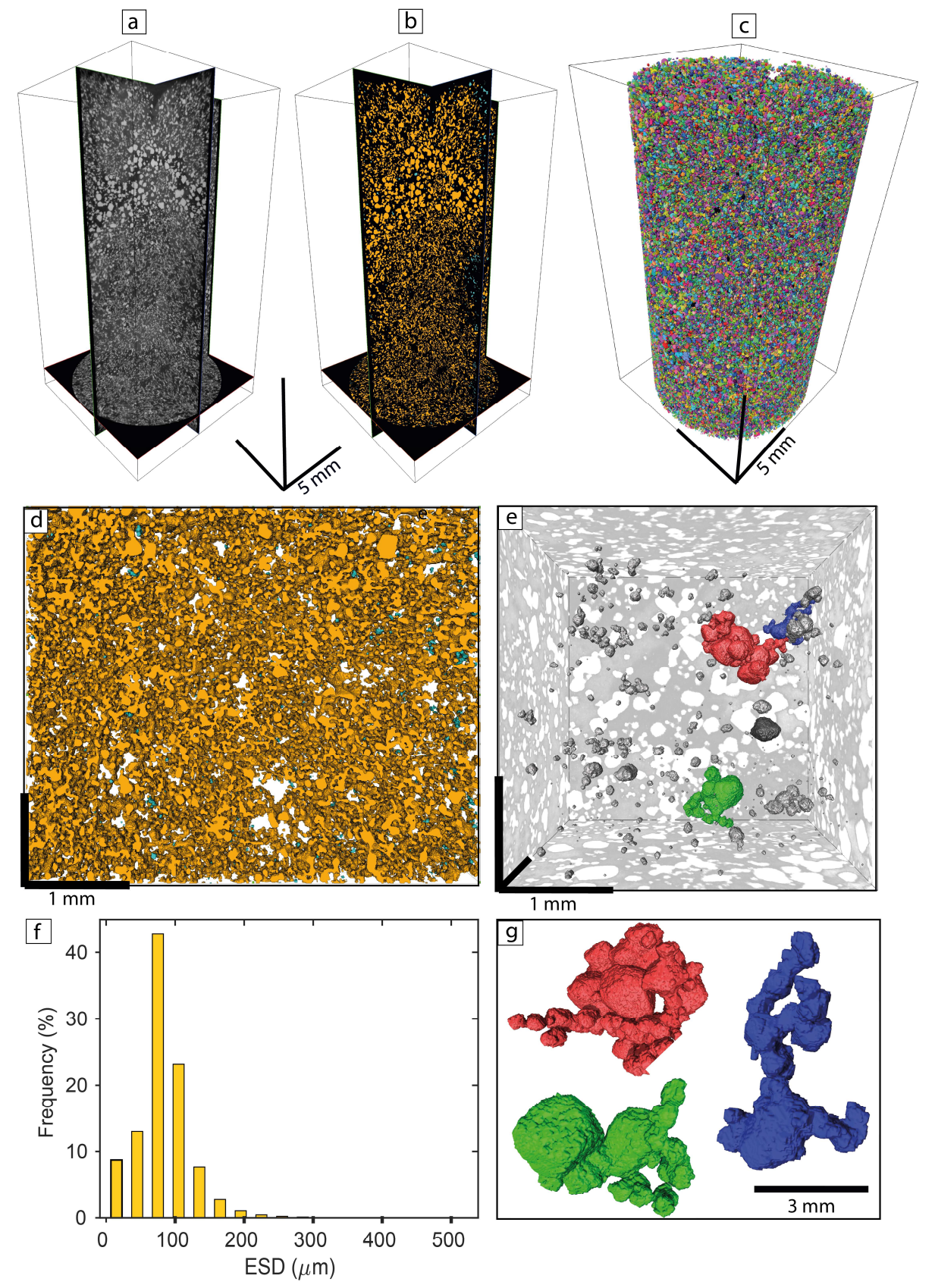

Fig. 2. Results of high-resolution X-ray computed tomography revealing that nearly all chromite grains in UG1 chromitite are interconnected within a continuous 3D framework. (a) Three orthogonal slices virtually cut through the UG1 sample (HX-07-153.33, Mototolo mine, Eastern Limb) showing chromite in light grey;(b) Segmented chromitite showing how a single interconnected network (coloured in yellow) covers the entire sample volume; (c) Volume rendering of chromite grains displayed using a false 256 colour scale; (d) Expanded view of a volume of interest showing details of the interconnected chromite network (orange) and the isolated chromite grains (in cyan); (e) and (g) Details of selected chromite cluster morphologies within the large interconnected chromite network where only a small number of grains are coloured to improve visibility; (f) Histogram showing the size distribution of chromite grains in the sample (ESD: equivalent sphere diameter). 

microstructures (Fig. 2) could be generated by random loose packing of non-interacting particles, i.e. from small independent chromite grains settling from a basaltic melt by gravity settling or kinetic sieving ${ }^{43}$. Theoretical microstructures of random mechanical crystal packs can be predicted by packing theory and characterised by two properties: the packing density (inverse of porosity); and the distribution of coordination numbers, i.e., the number of nearest neighbour grains in contact. Quantification of clustering and chain formation has typically used assumptions of constant grain sizes ${ }^{44}$ but these parameters are known to be sensitive to the particle size distribution $^{45}$. No observations or simulations have been made to date using the characteristic negative log-linear particle size distributions of crystals found in cumulates. To address this gap, we measured chromite particle sizes and coordination number distributions choosing a volume within which chromite grains are primarily enclosed within plagioclase or pyroxene oikocrysts. This is to eliminate possible effects on microstructure caused by later recrystallisation and annealing. We then compared the results with those of a Discrete Element Method $^{59,60}$ computer simulation of a random loose packing, generated by simple settling, of an assemblage of crystals with the same size distribution as the UG1 sample (Methods). Results show two distinct differences between the synthetic pack and the natural sample (Fig. 3): firstly, the packing densities are greatly different, being much higher in the synthetic pack than in the natural sample (60\% vs. $27 \%)$. Secondly, the distribution of coordination numbers is significantly different (Fig. 3b, c). In the random pack, coordination number increases exponentially with the grain size. This happens because, for the geometrical reasons, larger grains have a larger surface area and hence are likely to be in contact with a larger number of smaller grains filling space between them. In the natural UG1 data set, however, the coordination number flattens out and remains roughly constant at about 10 for grains larger 
than 150 microns in size (noting that only a small proportion of the total number of grains falls

172 in this size range). This results from the chromite grains forming an open cage-like or chain-

173 like structure where gaps in the framework are not occupied by other grains, causing lower

174 coordination numbers at larger grain sizes. Furthermore, the natural sample contains a

175 significant proportion of isolated or nearly isolated grains with coordination numbers of 0,1 or

176 2; these are absent in the simulation. We conclude that (a) the low packing density, (b) the

177 presence of isolated individual grains not supported by contact with any other chromite grains,

178 and (c) the relationship between coordination number and crystal size in the UG1 chromitite

179 are not consistent with random mechanical accumulation of non-interacting chromite grains,

180 be it crystal settling in a melt ${ }^{35-38}$ or kinetic sieving in a crystal mush ${ }^{39,40}$.

182 There remains a possibility that chromite may settle in the form of chromite chains/clusters 183 produced either by heterogeneous nucleation against chromite grains suspended in the 184 convecting melt ${ }^{46}$ or physical collision of isolated chromite crystals 'swimming together' in 185 this melt (i.e. "synneusis") ${ }^{47}$. The accumulation of such clustered chains on the chamber floor 186 may, in principle, give rise to the formation of a continuous 3D framework of touching 187 chromite crystals. However, we reject this scenario on the field evidence: neither individual 188 grains nor clustered chains can settle onto overhanging margins of potholes ${ }^{28,34}$ (Extended Data 189 Fig. 1). Sidewall crystallisation thus indicates that the 3D chromite framework has crystallized 190 in situ, i.e., directly at the chamber floor. This may only happen by one physical process 191 heterogeneous/self-nucleation ${ }^{22,46,48}$ of chromite grains on the floor cumulates ${ }^{28,34}$. To develop 192 this point further, we also compare the microstructure of a Merensky Reef chromitite seam that 

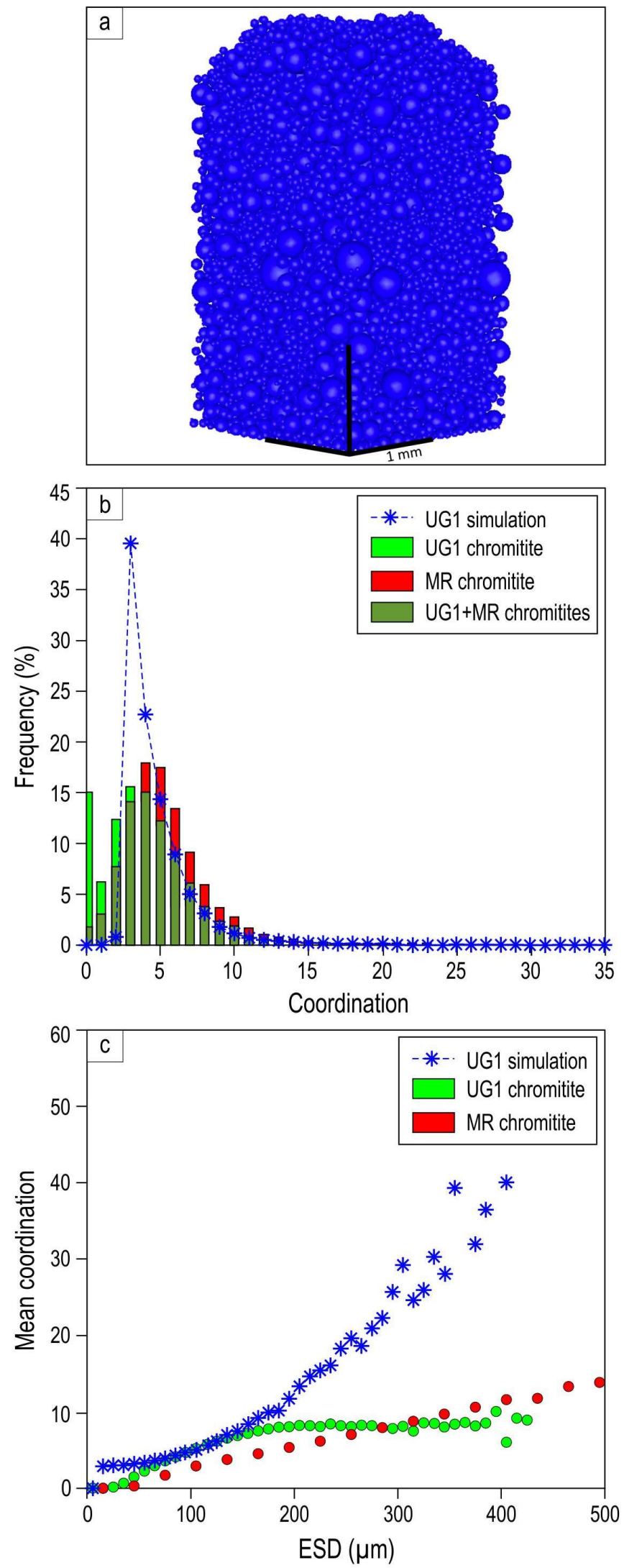

occurs on a vertical to overhanging sidewalls of potholes (Extended Data Figs. 3 and 4; Supplementary Video 1), taken as a definitive example of a microstructure that could only have developed in situ $^{34,49}$ (Fig. 3c).

Fig. 3. Results of numerical simulation compared to the observed natural data for the UG1 chromitite showing the contrasting relationship between grain size and coordination number between the randomised loose packing simulation (using the observed UG1 grain size distribution) and the two natural samples, the UG1 chromitite and MR overhanging chromitite. (a) 3D perspective view of a simulation pack of spheres having the same size distribution as chromite grains in the UG1 chromitite; (b) Histogram showing the distribution of coordination number in UG1 simulation, UG1 chromitite and MR overhanging chromitite; (c) Plot showing mean coordination number of all grains within each size range bin, as a function of size range of chromite grains in the UG1 simulation, UG1 chromitite and MR overhanging chromitite (ESD: equivalent sphere diameter). 
226 The packing density is likewise lower than the random loose packing simulation (53\% vs 60\%)

227 (Supplementary Data 1). The coordination number vs grain size curve for this seam shows a 228 steady linear increase with grain size, but, like the UG1 chromitite, has systematically lower coordination number values than the simulation along the entire length of the trend (Fig. $3 \mathrm{c}$ ). Significantly, the packing and coordination number characteristics of the UG1 chromitite are much closer to those of the indisputably in-situ crystallised sidewall Merensky Reef chromitite than to the random packing simulation. We deduce that the relatively low coordination number values and low packing densities of both natural samples are the result of in situ growth of chromite chains or cages by heterogeneous self-nucleation. We also conclude that chromite grains (Fig. 1d) are not able to settle freely towards the chamber floor simply because they are all bound together in self-supporting frameworks attached to the floor.

\section{A scenario for in situ growth of chromite on the chamber floor}

In situ growth of chromite requires crystallisation from a parental melt that was saturated in chromite as the only liquidus phase. Such melts can be produced in response to decompression during their ascent from a deep staging reservoir towards Earth's surface ${ }^{30}$. We propose that the Bushveld chamber has been replenished by such melts as basal flows that caused thermochemical erosion of the floor cumulates ${ }^{28}$, including the excavation of potholes (Fig. 4a). Upon cooling, the melt became saturated in chromite only ${ }^{30}$ (Fig. 4b), with the first chromite grains being nucleated heterogeneously on pre-existing plagioclase crystals of the floor anorthosites. With further cooling, chromite started preferentially self-nucleating on earlier-formed chromite grains to produce composite 3D clusters which subsequently merged into a continuous 3D framework of touching chromite grains (Fig. 4c). New crystals emerged in the system mostly by self-nucleation because the activation energy for this process is much lower relative to other types of nucleation ${ }^{22,46}$. A small portion of crystals ( 3 vol.\%) that occur 
251 as entirely discrete grains (Fig. 2d) has likely formed by homogeneous nucleation in the 252 interstitial space. We envisage that chemical differentiation of the resident melt in the chamber 253 at that time occurred by convective removal of a buoyant compositional boundary layer ${ }^{50}$ from 254 in situ growing chromite crystals in a 3D framework (Fig. 4c). The differentiation is aided by 255 high porosity and permeability of a 3D crystal framework that permits the easy chemical 256 exchange of melts between the crystal framework and the main magma body. The remarkable 257 preservation of the nucleation/growth history in the UG1 chromitite is due to the early growth 258 of plagioclase and pyroxene oikocrysts which have 'frozen in' a 3D chromite framework at its 259 early immature stage. This continuous 3D framework of chromite grains (Fig. 2) is the first 260 documented example showing how a natural solidification front looks when it develops via 261 self-nucleation/heterogeneous nucleation ${ }^{48}$. Under other circumstances, the initial framework 262 would have evolved into perfect chromitite adcumulate (up to 100\% chromite; e.g. LG 263 chromitite in Extended Data Fig. 5) in which all primary information is lost. We propose that 264 most layers of monomineralic chromitites in the Bushveld Complex started their life as porous, 265 in situ produced 3D chromite frameworks that can no longer be seen due to adcumulus 266 overgrowth ${ }^{51}$. We further propose that the observed shape of the coordination number vs grain 267 size curve (Fig. 3c) may be diagnostic of chromite cumulates formed by in situ crystallisation 268 involving heterogeneous self-nucleation ${ }^{28,34}$.

\section{Chromium budget requires a large magma volume}

271 The realization that massive chromitites form by in situ growth of chromite directly in the 272 chamber (Fig. 4a) - rather than from chromite phenocrysts brought into the chamber with 273 externally-derived crystal-rich mushes ${ }^{9,12,38,40}$ - logically brings us to a long-known Cr mass

274 balance issue $32,52,53$. The stratiform chromitite layers in layered intrusions can be up to $2 \mathrm{~m}$ 275 thick and contain $40-50$ wt. $\% \mathrm{Cr}_{2} \mathrm{O}_{3}$, yet have evidently crystallized from a basaltic melt that 
276 was unlikely to have contained more than $1000 \mathrm{ppm}^{31}$. An implication is that the formation 277 of a thick chromitite layer, such as the UG1 chromitite, requires extraction of Cr from a very 278 large volume of liquid that can be present either as a thick melt layer in the chamber or as the 279 melt flowing through the chamber, or both. To illustrate, given the thickness of a chromite 280 layer, from mass-balance considerations one can calculate the volume of the parental melt in 281 terms of the thickness of an equivalent layer. If a chromite layer crystallized at $1250^{\circ} \mathrm{C}$ and the $282 f \mathrm{O}_{2}$ equivalent to QFM buffer, then based on experimental data ${ }^{31,52}$, the chromite should contain $283 \sim 45 \% \mathrm{Cr}_{2} \mathrm{O}_{3}$, and the coexisting melt should carry about $0.10 \mathrm{wt} \% \mathrm{Cr}_{2} \mathrm{O}_{3}$. Assuming that 284 chromitites formed from the overlying melt, it can be estimated that a $1 \mathrm{~m}$ thick layer of 285 chromitite will require a magma column of about $4 \mathrm{~km}$ thick (Fig. 4a). The thickness can be 286 reduced to $2 \mathrm{~km}^{32}$ or $1 \mathrm{~km}^{26}$ if $\mathrm{Cr}$ solubility in a parental melt is to increase by its higher 287 temperature or lower $f \mathrm{O}_{2}{ }^{32}$. These estimations assume $30 \%$ of the $\mathrm{Cr}$ removal from a parental $288 \mathrm{melt}^{32}$. One cannot remove any more $\mathrm{Cr}$ from the melt than that because otherwise the melt 289 will reach a cotectic with other liquidus phases (e.g., olivine or orthopyroxene) terminating chromitite formation (Fig. 4b).

This one-dimensional modelling illustrates the mass-balance issue. Applying this logic to the Bushveld Complex, it has been estimated that the formation of its most prominent chromitites would have required a column of 13 to $15 \mathrm{~km}$ of a parental chromite-saturated liquid ${ }^{25,26}$. In addressing this mass-balance requirement, Cawthorn and Walraven ${ }^{25}$ modelled the Bushveld chamber as a long-lived flow-through system $(\sim 75,000$ years life-time $)$ that developed via a large number of injection events, partial crystallization of these magma batches, and removal of their residual liquids from the chamber by the succeeding magma batches. They concluded that the total volume of basaltic magma involved was $740-1200 * 10^{3} \mathrm{~km}^{3}$, with only $\sim 50 \%$ of this being represented by the cumulates now seen within the Bushveld Complex ${ }^{25}$. The excess 


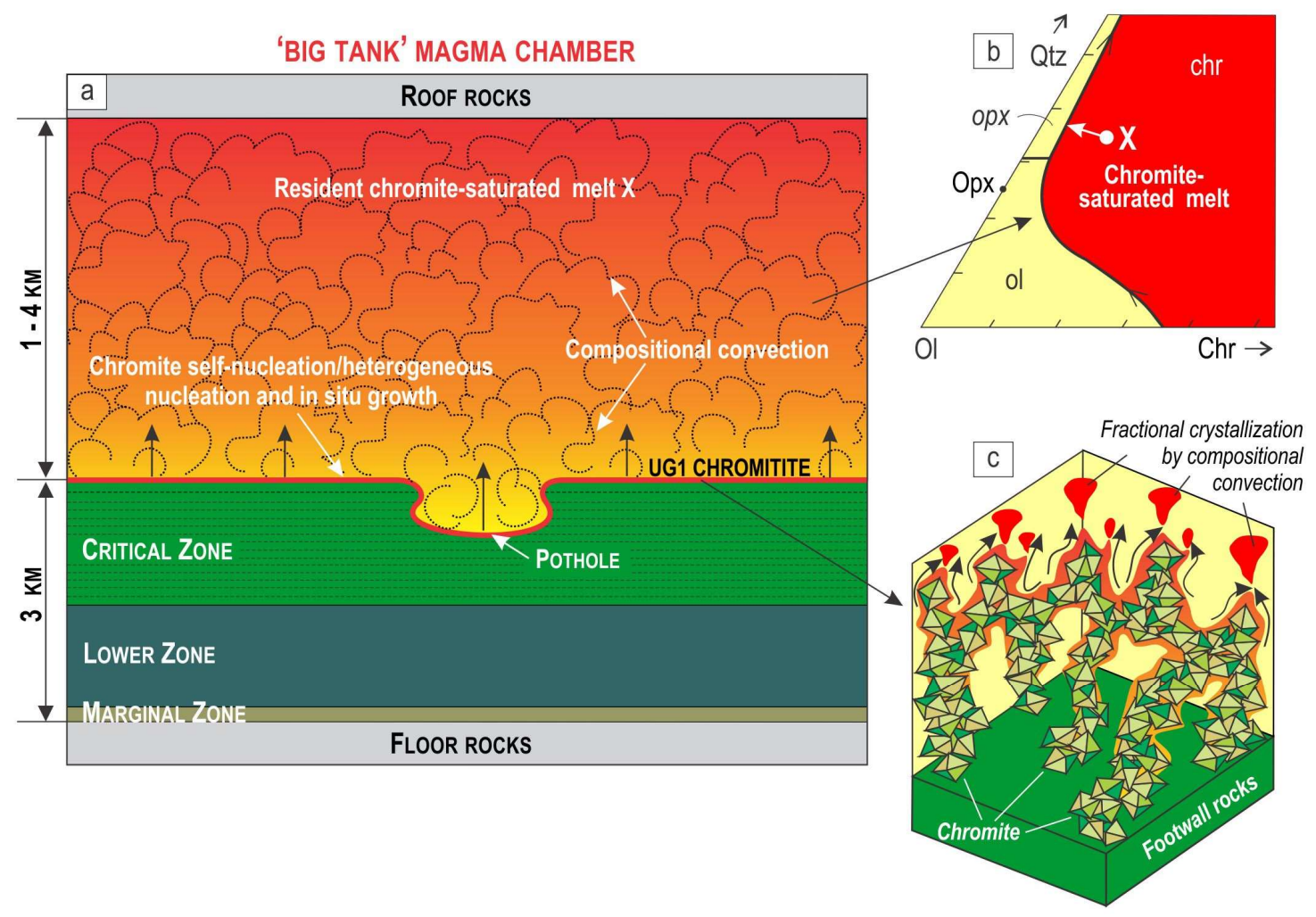

Fig. 4. A 'big-tank' chamber of the Bushveld Complex filled with a resident melt that crystallizes into the

UG1 chromitite at the chamber floor. a, Schematic cartoon of the Bushveld chamber that shows crystallization of the UG1 chromitite near the top of the Critical Zone. The formation of a $1 \mathrm{~m}$ thick layer of such chromitite requires an equivalent layer of chromite-only-saturated melt of at least 1 to $4 \mathrm{~km}$ in thickness ${ }^{31,32}$. This large volume of liquid may be present in the chamber either as a melt column or as a melt that flows through the chamber for a long period of time. The chromite nucleates and crystallizes directly on the chamber floor, with the resident melt convecting turbulently to deliver $\mathrm{Cr}$ for in situ chromite growth. b, Ol-Chr-Qtz phase diagram illustrating the position of a chromite-only-saturated melt parental to the UG1 chromitite. The diagram is modified from reference ${ }^{35}$. Ol, olivine; Opx, orthopyroxene, Chr, chromite; Qtz, quartz. c, A close-up view of the immature UG1 chromitite that forms a 3D framework of touching chromite crystals which self-nucleate on the floor of a magma chamber. Note the low density packing and the low coordination number of chromite in the framework. A compositional boundary layer of buoyant liquid is produced around crystallizing chromite clusters that migrates towards their apex and is released into the overlying melt in the form of compositional plumes, thus causing chemical differentiation in the resident melt. 


\section{A classical magma chamber paradigm affirmed}

322 The enormous lateral extent of in situ formed chromitite layers and related mass-balance

323

324

325

326

327

328

329

330

331

332

333

334

335

336

337

338

339

340

341

342

343

344

345 considerations indicate that during the formation of massive chromitites the Bushveld chamber has been operating as a giant magma body of more than $400 \mathrm{~km}$ in diameter, with a column of the resident melt likely attaining a few $\mathrm{km}$ in thickness. Thus, starting from this stage the Bushveld Complex has been developed as a large, long-lived and largely molten magma chamber (a true 'big tank' reservoir) in Earth's crust (Fig. 4a). The conclusion is further supported by the remarkable homogeneity of $\mathrm{Sr}$ isotopes over an interval of more than $2.5 \mathrm{~km}$ of the Upper Zone ${ }^{56}$, which indicates a melt column thickness in the chamber being that thick or even thicker ${ }^{57,58}$. This is in contrast with the recent assertion, mostly based on out-ofsequence geochronology 9,13 , that depicts this giant complex as a stack of thin crystal-rich sills $^{9,11,13}$. Field relationships indicate, however, that zircon isotopic ages in these studies were almost certainly misinterpreted ${ }^{59}$. We thus argue that the field and textural evidence from massive chromitites disprove this radical re-interpretation of the Bushveld Complex. Our inference may be extended to all large mafic-ultramafic layered intrusions that contained thick and laterally extensive layers of monomineralic chromitites (e.g., Stillwater and Great Dyke). Such intrusions are quite rare in the crust through the whole of geological time, so it is not surprising that there are no known examples of equivalent magma chambers that are active and detectable in the present-day Earth's crust ${ }^{4,8}$. We conclude that it is too early to discard the classical paradigm of a magma chamber developed by several generations of petrological luminaries $^{14-19}$. Rather, we suggest re-directing our efforts to find out how new geophysical, geochronological and thermal/diffusion modelling ${ }^{1-13}$ can be logically reconciled with the classical paradigm. 
347 Any methods, additional references, Nature Research reporting summaries, source data,

extended data, supplementary information, acknowledgements, peer review information;

details of author contributions and competing interests; and statements of data and code

availability are available at....

\section{References}

1. Glazner, A. F., Coleman, D. S., Gray, W. \& Taylor, R. Z. Are plutons assembled over millions of years by amalgamation from small magma chambers? GSA TODAY 14, 4-12 (2004).

2. Coleman, D. S., Gray, W. \& Glazner, A. F. Rethinking the emplacement and evolution of zoned plutons: geochronologic evidence for incremental assembly of the Tuolumne Intrusive Suite, California. Geol 32, 433 (2004).

3. Bachmann, O. \& Huber, C. The inner workings of crustal distillation columns; the physical mechanisms and rates controlling phase separation in silicic magma reservoirs. Journal of Petrology 60, 3-18 (2019).

4. Cashman, K. V., Sparks, R. S. J. \& Blundy, J. D. Vertically extensive and unstable magmatic systems: a unified view of igneous processes. Science 355, eaag3055 (2017).

5. Cooper, K. M. What does a magma reservoir look like? The "crystal's-eye" view. Elements 13, 23-28 (2017).

6. Edmonds, M., Cashman, K. V., Holness, M. \& Jackson, M. Architecture and dynamics of magma reservoirs. Phil. Trans. R. Soc. A. 377, 20180298 (2019).

7. Jackson, M. D., Blundy, J. \& Sparks, R. S. J. Chemical differentiation, cold storage and remobilization of magma in the Earth's crust. Nature 564, 405-409 (2018).

8. Sparks, R. S. J. et al. Formation and dynamics of magma reservoirs. Phil. Trans. R. Soc. A. 377, 20180019 (2019).

9. Mungall, J. E., Kamo, S. L. \& McQuade, S. U-Pb geochronology documents out-of-sequence emplacement of ultramafic layers in the Bushveld Igneous Complex of South Africa. Nat Commun 7, 13385 (2016).

10. Wall, C. J. et al. The Stillwater Complex: integrating zircon geochronological and geochemical constraints on the age, emplacement history and crystallization of a large, open-system layered intrusion. Journal of Petrology 59, 153-190 (2018).

11. Robb, S. J. \& Mungall, J. E. Testing emplacement models for the Rustenburg Layered Suite of the Bushveld Complex with numerical heat flow models and plagioclase geospeedometry. Earth and Planetary Science Letters 534, 116084 (2020).

12. Yao, Z., Mungall, J. E. \& Jenkins, M. C. The Rustenburg Layered Suite formed as a stack of mush with transient magma chambers. Nat Commun 12, 505 (2021).

13. Scoates, J. S. et al. Dating the Bushveld Complex: timing of crystallization, duration of magmatism, and cooling of the world's largest layered intrusion and related rocks. Journal of Petrology (2021) doi:10.1093/petrology/egaa107.

14. Daly, R. A. The nature of volcanic action. Proceedings of the American Academy of Arts and Sciences 47, 48-119 (1911).

15. Bowen, N. L. The evolution of the igneous rocks. (Oxford University Press, 1928).

16. Wager, L. R. \& Deer, W. A. Geological Investigations in East Greenland, Part III: The Petrology of the Skaergaard Intrusion, Kangerdlugssuaq, East Greenland. Med. Greenland 105, 352 (1939).

17. Wager, L. R. \& Brown, G. M. Layered igneous rocks. (Oliver \& Boyd, Edinburgh \& London, 1968). 
18. Parsons, I. Origins of Igneous Layering. vol. 196 (Springer, Dordrecht, 1987).

19. Cawthorn, R. G. Layered Intrusions. vol. 15 (Elsevier, Amsterdam, 1996).

20. Charlier, B., Namur, O., Latypov, R. \& Tegner, C. Layered Intrusions. (Springer Netherlands, 2015).

21. Marsh, B. D. Solidification fronts and magmatic evolution. Mineralogical Magazine 60, 5-40 (1996).

22. Campbell, I. H. Fluid Dynamic Processes in Basaltic Magma Chambers. in Developments in Petrology vol. 15 45-76 (Elsevier, 1996).

23. Gudmundsson, A. Magma chambers: formation, local stresses, excess pressures, and compartments. Journal of Volcanology and Geothermal Research 237-238, 19-41 (2012).

24. Cawthorn, R. G. The Bushveld Complex, South Africa. in Layered Intrusions (eds. Charlier, B., Namur, O., Latypov, R. \& Tegner, C.) 517-587 (Springer Netherlands, 2015). doi:10.1007/978-94017-9652-1_12.

25. Cawthorn, R. G. \& Walraven, F. Emplacement and crystallization time for the Bushveld Complex. Journal of Petrology 39, 1669-1687 (1998).

26. Naldrett, A. J., Wilson, A., Kinnaird, J., Yudovskaya, M. \& Chunnett, G. The origin of chromitites and related PGE mineralization in the Bushveld Complex: new mineralogical and petrological constraints. Mineralium Deposita 47, 209-232 (2012).

27. Schurmann, L. W., Grabe, P.-J. \& Steenkamp, C. J. Chromium. in The Mineral Resources of South Africa vol. 16 90-105 (Council for Geosciences, 1998).

28. Latypov, R., Chistyakova, S. \& Mukherjee, R. A novel hypothesis for origin of massive chromitites in the Bushveld Igneous Complex. Journal of Petrology 58, 1899-1940 (2017).

29. Pebane, M. \& Latypov, R. The significance of magmatic erosion for bifurcation of UG1 chromitite layers in the Bushveld Complex. Ore Geology Reviews 90, 65-93 (2017).

30. Latypov, R. et al. Platinum-bearing chromite layers are caused by pressure reduction during magma ascent. Nature Communications 9, (2018).

31. Murck, B. W. \& Campbell, I. H. The effects of temperature, oxygen fugacity and melt composition on the behaviour of chromium in basic and ultrabasic melts. Geochimica et Cosmochimica Acta 50, 1871-1887 (1986).

32. Campbell, I. H. \& Murck, B. W. Petrology of the G and H Chromitite Zones in the Mountain View Area of the Stillwater Complex, Montana. Journal of Petrology 34, 291-316 (1993).

33. Cawthorn, R. G. The platinum group element deposits of the Bushveld Complex in South Africa. platin met rev 54, 205-215 (2010).

34. Latypov, R., Chistyakova, S., Barnes, S. J. \& Hunt, E. J. Origin of platinum deposits in layered intrusions by in situ crystallization: Evidence from undercutting Merensky Reef of the Bushveld Complex. Journal of Petrology (2017) doi:10.1093/petrology/egx032.

35. Irvine, T. N. Origin of chromitite layers in the Muskox intrusion and other stratiform intrusions: A new interpretation. Geology 5, 273-277 (1977).

36. Spandler, C., Mavrogenes, J. \& Arculus, R. Origin of chromitites in layered intrusions: Evidence from chromite-hosted melt inclusions from the Stillwater Complex. Geology 33, 893-896 (2005).

37. Kinnaird, J. A., Kruger, F. J., Nex, P. A. M. \& Cawthorn, R. G. Chromitite formation-a key to understanding processes of platinum enrichment. Applied Earth Science 111, 23-35 (2002).

38. Lesher, C. M., Carson, H. J. E. \& Houlé, M. G. Genesis of chromite deposits by dynamic upgrading of Fe \pm Ti oxide xenocrysts. Geology 47, 207-210 (2019).

39. Maier, W. D., Barnes, S.-J. \& Groves, D. I. The Bushveld Complex, South Africa: formation of platinum-palladium, chrome- and vanadium-rich layers via hydrodynamic sorting of a mobilized cumulate slurry in a large, relatively slowly cooling, subsiding magma chamber. Mineralium Deposita 48, 1-56 (2013).

40. Mondal, S. K. \& Mathez, E. A. Origin of the UG2 chromitite layer, Bushveld Complex. Journal of Petrology 48, 495-510 (2007). 
41. Jackson, E. D. Primary textures and mineral associations in the ultramafic zone of the Stillwater complex, Montana. Professional Paper 106 https://pubs.er.usgs.gov/publication/pp358 (1961) doi:10.3133/pp358.

42. Eales, H. V. \& Reynolds, I. M. Cryptic variations within chromitites of the upper critical zone, northwestern Bushveld Complex. Economic Geology 81, 1056-1066 (1986).

43. Delaney, G. W., Hilton, J. E. \& Cleary, P. W. Defining random loose packing for nonspherical grains. Phys. Rev. E 83, 051305 (2011).

44. Jerram, D. A. Quantifying the Building Blocks of Igneous Rocks: Are Clustered Crystal Frameworks the Foundation? Journal of Petrology 44, 2033-2051 (2003).

45. He, D., Ekere, N. N. \& Cai, L. Computer simulation of random packing of unequal particles. Phys. Rev. E 60, 7098-7104 (1999).

46. Campbell, I. H. Some problems with the cumulus theory. Lithos 11, 311-323 (1978).

47. Philpotts, A. R., Shi, J. \& Brustman, C. Role of plagioclase crystal chains in the differentiation of partly crystallized basaltic magma. Nature 395, 343-346 (1998).

48. Latypov, R. M., Chistyakova, S. Yu., Namur, O. \& Barnes, S. Dynamics of evolving magma chambers: textural and chemical evolution of cumulates at the arrival of new liquidus phases. Earth-Science Reviews 210, 103388 (2020).

49. Latypov, R., Chistyakova, S., Page, A. \& Hornsey, R. Field evidence for the in situ crystallization of the Merensky Reef. Journal of Petrology egv023 (2015) doi:10.1093/petrology/egv023.

50. Kruger, W. \& Latypov, R. Fossilized solidification fronts in the Bushveld Complex argue for liquiddominated magmatic systems. Nat Commun 11, 2909 (2020).

51. Campbell, I. H. Distribution of orthocumulate textures in the Jimberlana intrusion. The Journal of Geology 95, 35-53 (1987).

52. Barnes, S. J. The distribution of chromium among orthopyroxene, spinel and silicate liquid at atmospheric pressure. Geochimica et Cosmohimica Acta 50, 1889-1909 (1986).

53. Eales, H. V. Implications of the chromium budget of the Western Limb of the Bushveld Complex. South African Journal of Geology 103, 141-150 (2000).

54. Prendergast, M. D. The Molopo Farms Complex, southern Botswana - a reconsideration of structure, evolution, and the Bushveld connection. South African Journal of Geology 115, 77-90 (2012).

55. Kaavera, J., Rajesh, H. M., Tsunogae, T. \& Belyanin, G. A. Marginal facies and compositional equivalents of Bushveld parental sills from the Molopo Farms Complex layered intrusion, Botswana: Petrogenetic and mineralization implications. Ore Geology Reviews 92, 506-528 (2018).

56. Kruger, F. J., Cawthorn, R. G. \& Walsh, K. L. Strontium isotopic evidence against magma addition in the Upper Zone of the Bushveld Complex. Earth and Planetary Science Letters 84, 51-58 (1987).

57. Vantongeren, J. A., Mathez, E. A. \& Kelemen, P. B. A felsic end to Bushveld differentiation. Journal of Petrology 51, 1891-1912 (2010).

58. Vantongeren, J. A. \& Mathez, E. A. Incoming Magma Composition and Style of Recharge below the Pyroxenite Marker, Eastern Bushveld Complex, South Africa. Journal of Petrology 54, 15851605 (2013).

59. Latypov, R. M. Misleading interpretation of zircon ages in layered intrusions: A discussion on "Dating the Bushveld Complex: Timing of Crystallization, Duration of Magmatism, and Cooling of the World's Largest Layered Intrusion and Related Rocks" by James S. Scoates et al. (J. Petrology, 2021). (2021). 
492 Rock sampling and petrography

493 Documentation of field observations of the UG1 chromitite was undertaken at the Dwars River 494 locality and its sampling at the nearby Mototolo Mine from the HEX 076 drill-core in the 495 Eastern Bushveld Complex. Thin sections and polished blocks were cut from orientated sample 496 blocks to be as close as possible to the original vertical position. Thin sections and polished 497 blocks were studied using a polarised light microscope with a circular stage and photographed 498 using the Olympus 224 BX-63 OM/FM optical microscope housed at the MMU (Microscopy 499 and Microanalysis Unit) of the University of the Witwatersrand, Johannesburg, South Africa.

\section{High resolution X-ray computed tomography and 3D image analysis and quantification}

502 The UG1 sample was scanned using the Zeiss Versa XRM 520 3D x-ray microscope installed

503 at the Australian Resources Research Centre (CSIRO Mineral Resources, Kensington, 504 Western-Australia). The instrument was set to maximize the contrast between chromite and 505 silicates (plagioclase and pyroxene) present in the sample. Two scans at a voxel size of $5 \mu \mathrm{m}$ 506 were performed along the vertical axis of the samples and were stitched in $3 \mathrm{D}$ to maximize the 507 volume of sample used for further analysis. A total of 1601 projections were recorded over $508360^{\circ}$ degrees rotation for each scan and were used for volume reconstruction. Beam hardening 509 and ring artefacts were minimized during data acquisition and corrected (if necessary) during 510 image reconstruction. After reconstruction, the sample is represented by a regular grid (1998 $\mathrm{x}$ 5112046 x 3748 voxels) where each voxel has a unique greyscale value. Chromite, plagioclase and 512 pyroxene were segmented from the volumes using a $3 \mathrm{D}$ gradient watershed algorithm ${ }^{60}$ to 513 produce binary images. The separation of touching chromite crystals in $3 \mathrm{D}$ was done using a 514 modified version of the algorithm used to separate touching chromite in komatiites ${ }^{61}$ and 515 chromite from the normal Merensky Reef ${ }^{62}$ using Avizo2020.1 ${ }^{\mathrm{TM}}$ and Matlab ${ }^{\mathrm{TM}}$ software. The 
shape and size characteristics of chromite network and individual grains were computed to provide quantitative measure of chromite grains above $15 \mu \mathrm{m}$ equivalent sphere diameter (ESD). Chromite grains were defined as touching each other using an 18-voxel connectivity threshold (i.e., voxels are connected if their faces or edges touch). The coordination number of each chromite grains (i.e., the total number of other chromite grains touching in 3D a given grain) was also calculated. All results are summarized in Figs. 2 and 3.

\section{Random packing simulation}

The simulated Random Packing of UG1 chromite was generated using the Discrete Element Method as described in ref ${ }^{63}$. The individual chromite particles were modelled as spheres with a size distribution as measured from the UG1 chromite sample ranging from $15 \mu \mathrm{m}$ to $420 \mu \mathrm{m}$, and an interparticle friction coefficient of 0.9 . The simulation box has dimensions $5 \mathrm{~mm}$ by 2 $\mathrm{mm}$ by $2 \mathrm{~mm}$, with periodic boundaries in the two directions normal to gravity. Particles are initially distributed randomly in the simulation box and then allowed to slowly settle under gravity subject to a Stokes' drag force to form a random loose packing ${ }^{43}$. The packing is then analysed to determine the packing density and the distribution of inter-particle contacts between particles.

\section{References}

60. Godel, B. High-Resolution X-Ray Computed Tomography and Its Application to Ore Deposits: From Data Acquisition to Quantitative Three-Dimensional Measurements with Case Studies from Ni-Cu-PGE Deposits. Economic Geology 108, 2005-2019 (2013).

61. Godel, B., Barnes, S. J., Gürer, D., Austin, P. \& Fiorentini, M. L. Chromite in komatiites: 3D morphologies with implications for crystallization mechanisms. Contrib Mineral Petrol 165, 173189 (2013).

62. Vukmanovic, Z., Barnes, S. J., Reddy, S. M., Godel, B. \& Fiorentini, M. L. Morphology and microstructure of chromite crystals in chromitites from the Merensky Reef (Bushveld Complex, South Africa). Contributions to Mineralogy and Petrology 165, 1031-1050 (2012).

63. Cleary, P. W. Large scale industrial DEM modelling. Engineering Computations 21, 169-204 (2004). 
549 The authors declare that all relevant data are available within the article and its Supplementary 550 Information Files.

551

552 Acknowledgements Several versions of this manuscript benefited from the constructive peer reviews by 553 Catherine Annen, Allen Glazner, Chris Hawkesworth, Olivier Namur, Jill VanTongeren, Zoja Vukmanovic, 554 Steve Prevec and Willem Kruger. The study was supported by research grants to R.L. from the National 555 Research Foundation (NRF) and Department of Science and Technology (DST)-NRF Centre of Excellence 556 for Integrated Mineral and Energy Resource Analysis (CIMERA) of South Africa. V.J.R. was supported by 557 the DST-NRF Centre of Excellence in Palaeosciences (CoE-Pal), and the Palaeontological Scientific Trust 558 (PaST). Any opinion, finding and conclusion or recommendation expressed in this contribution is that of the 559 authors and the DST-NRF CIMERA, CoE-Pal, PaST and NRF do not accept any liability in this regard. We 560 thank an artist Inna Laur (Finland) for helping us depict the 3D framework of touching chromite crystals in 561 Fig. $4 \mathrm{c}$.

Author Contributions R.L. and S.C. undertook field work, mapping and geochemical sampling of outcrops as well as conceptualized the original idea and wrote a draft of the paper. V.R. and K.J. performed X-ray microtomography of samples and data processing, took part in conceptualizing the original idea and participated to the text writing. B.G. collected, processed, and analysed the HRXCT data. G. D., P. C. and

567 S.B. have conducted the randomised loose packing simulation of chromite grains in the UG1 chromitite. 568 S.B. and I.C. participated in interpretation of data, editing the paper as well as in improving clarity of figures. 569 All co-authors discussed the results and problems and contributed to producing a final draft for peer reviews.

571 Supplementary Information is available in the online version of the paper.

572

573 Competing interests The authors declare no competing interests. 


\section{Supplementary Files}

This is a list of supplementary files associated with this preprint. Click to download.

- SupplementaryData1.xlsx

- ExtendedData.pdf

- SupplementaryVideo1UG1 chromitite.zip

- SupplementaryVideo2MRchromitite.zip 